\title{
Mixed Lymphocyte Cultures in Rheumatoid Arthritis
}

\author{
Peter Stastny \\ From the Department of Internal Medicine, Transplantation Immunology \\ Section, The University of Texas Health Science Center Dallas, Texas 75235
}

\begin{abstract}
A в S T R A C T Random one-way microtiter mixed lymphocyte cultures between 43 rheumatoid arthritis (RA) patients and 45 controls consisting of 26 normal subjects and 19 miscellaneous non-RA patients were performed and results were evaluated as relative responses. Low responses (consisting of relative response $<38 \%$ ) were found in 31 out of $43 \mathrm{RA}$ patients in cultures against eight of the RA stimulators. The remaining 35 RA stimulators tested yielded only normal mixed lymphocyte culture reactions. The same RA patients used as responders never produced low responses when stimulated by non-RA lymphocytes. But six of the control subjects gave low responses to two RA stimulators. The low responses did not appear to correlate with intake of aspirin, prednisolone, or gold salts, nor could they be reproduced by addition of RA serum or $7 \mathrm{~S}$ or $19 \mathrm{~S}$ fractions thereof containing either polyclonal or monoclonal rheumatoid factors. Short-term culture and washing before mixing with the allogeneic cells did not change the low responses suggesting that in vivo bound autoantibodies against lymphocyte receptors were not involved.

Study of the inheritance of HLA and mixed lymphocyte culture determinants in the family of patient A. C. who most frequently elicited low responses indicated she was homozygous for a lymphocyte-defined determinant which has been called $\mathrm{R}$. The low responses to A. C. could be interpreted as typing responses based on sharing of the same or of a similar lymphocyte-defined determinant. This gene appears to be increased in patients with RA with respect to non-RA controls and may reflect an association of genes within the HLA chromosomal region leading to predisposition for the development of RA.
\end{abstract}

\section{INTRODUCTION}

Patients with rheumatoid arthritis (RA) ${ }^{1}$ manifest various abnormal immunologic activities such as production

\footnotetext{
Received for publication 5 September 1975 and in revised form 7 January 1976.

${ }^{1}$ Abbreviations used in this paper: LD, lymphocyte defined; MLC, mixed lymphocyte culture; RA, rheumatoid arthritis.
}

of rheumatoid factors, diffuse hyperplasia of lymphoid tissue, and overt changes in the synovial membrane of involved joints that characterize an ongoing immune response (1). Both thymus-derived and bone marrowderived lymphocytes have been shown to be present in the lesions $(2-4)$ and their secretion products have been found in synovial fluids and in cultures of explants of synovial tissues. Thus, rheumatoid synovium produces immunoglobulin in large amounts (5) and the joint fluids have been shown to contain lymphokine-like materials (6). In other studies it was found that peripheral blood lymphocytes from patients with RA were unreactive in mixed lymphocyte cultures (MLC) against cells from other RA patients ( 7 ) however the mechanism of unreactivity was not elucidated. One hypothesis was that it reflects an abnormality in the function of lymphocytes or of phagocytic cells and therefore perhaps manifestation of a defect of cellular immunity associated with pathogenesis of the disease (8). Reactions in MLCs are known to result from recognition of the lymphocytedefined (LD) histocompatibility determinants which are products of loci close to, but separate from the A (LA), $\mathrm{B}$ (Four), and $\mathrm{C}(\mathrm{AJ})$ loci of the HLA region, (9-11), Typing for these determinants is now made possible through the use of LD homozygous MLC-typing cells (12-15). In the present work methods commonly used in histocompatibility studies were applied to the investigation of MLC reactions of lymphocytes in patients with RA. In preliminary experiments (16), low MLC reactions occurred in a small group of random RA patients and it was suggested that they may represent LD-typing responses. The results obtained subsequently in a larger group indicate that the low responses followed definable patterns and did not appear to be due to extrinsic factors or cellular defects, but rather depended on the sharing of genetically determined LD determinants among RA patients.

\section{METHODS}

Study subjects. RA patients in this study were 50 persons with classical or definite RA who attended the Arthritis Clinic at Parkland Memorial Hospital, Dallas, Tex. All of them were adults from 19 to $81 \mathrm{yr}$ of age. All except eight had positive latex and sheep cell agglutination 
tests for rheumatoid factor. Of these patients 26 were white, 14 were black, 9 were Latin American, and 1 was of American Indian background. At the time of the study most of them were taking aspirin, some were also treated with indomethacin or small doses (less than $10 \mathrm{mg} / \mathrm{day}$ ) of prednisolone, and about half of the patients were receiving injections of gold salts. A group of 50 nonrheumatoid subjects was also studied. These controls consisted of 24 patients with miscellaneous conditions other than RA and 26 normal subjects including laboratory personnel and normal relatives of kidney transplant recipients. Also studied were the members of a family of a patient (A. C.) with RA consisting of 12 nonaffected relatives of three generations. In addition, MLC results in 35 families of kidney transplant recipients were analyzed to test the effect of expressing results as relative responses.

MLCs. The MLC tests were performed using a microtiter plate technique (17) with some modifications. Blood was drawn into an equal volume of heparinized medium RPMI 1640 and lymphocytes were separated by flotation on FicollHypaque (Lymphoprep, Nyegaard, Oslo) as described by Böyum (18). The cells were washed once in RPMI 1640, buffered with bicarbonate $(24 \mathrm{mM})$ and Hepes $(20 \mathrm{mM})$, and then resuspended in the same medium containing $10 \%$ pooled normal human serum to a concentration of $5 \times 10^{\circ}$ mononuclear cells $/ \mathrm{ml}$. In earlier experiments, stimulating cells were treated with mitomycin $C$. In more recent experiments they were $X$-irradiated with 3,000 rads using a ${ }^{187} \mathrm{Cs}$ source which delivers $110 \mathrm{rads} / \mathrm{min}$. Both procedures were found to give equivalent results but the latter was more convenient when performing large cultures. Cultures were performed in round-bottomed Linbro microtiter plates (Linbro Chemical Co., New Haven, Conn. IS-MRC-96-TC). Each reaction well contained $5 \times 10^{4}$ responding and $5 \times 10^{4}$ stimulating cells in a total volume of $0.2 \mathrm{ml}$. Triplicate plates were incubated at $37^{\circ} \mathrm{C}$ in a moist atmosphere containing $5 \% \mathrm{CO}_{2}, 95 \%$ air. On the evening of the 6th day, tritiated thymidine $2 \mu \mathrm{Ci}$ sp act $5.0 \mathrm{Ci} / \mathrm{mmol}$ was added to each well and $16 \mathrm{~h}$ later the cells were harvested using a multiple sample harvesting device (17) of our own design. Glass fiber filters (Reeve-Angel 943AH) containing the harvested lymphocytes were dried and then transferred to scintillation vials for counting with $5 \mathrm{ml}$ of liquifluor (New England Nuclear, Boston, Mass.) in a liquid scintillation counter.

Results were expressed in the form of relative responses (13). This was found to be most suitable for evaluation of results because it largely eliminates the effect of day-today variation in the level of tritiated thymidine incorporation. The basis of the calculations was the median of the triplicate counts for each culture combination. Several unrelated stimulating cells were included in each experiment to serve as reference for normalization. The median of these normal 2-haplotype responses was used in the formula for calculation of relative responses as follows:

Relative Response (\%)

$$
=\frac{\mathrm{cpm} \text { stimulated culture }- \text { medium control }}{\mathrm{cpm} \text { normal 2-haplo response }- \text { medium control }} \times 100 \text {. }
$$

The relative response therefore was expressed as a percentage of the normal 2-haplotype response of each cell which was obtained from the control cultures. The stimulation index was also calculated using the formula: Stimulation Index $=\mathrm{ABm} / \mathrm{AAm}$ in which $\mathrm{ABm}$ represents counts per minute in the stimulated culture and AAm, counts per minute obtained in the autologous control.
The lymphocytes used in many experiments were preserved frozen in liquid nitrogen. Results obtained with fresh and with frozen lymphocytes showed that although absolute counts per minute were somewhat lower in cultures using frozen and thawed cells, the relative response values and the final interpretation remained unchanged. For freezing, lymphocytes were mixed slowly with dimethyl sulfoxide (7\%) and normal human serum $(10 \%)$ to a final concentration of $4-6 \times 10^{\circ}$ cells $/ \mathrm{ml}$. 1-ml portions were placed in 2-ml screw-cap plastic tubes with silicone washers (Nunc, Roskilde, Denmark) and cooled at a rate of $1^{\circ} \mathrm{C} / \mathrm{min}$ in a controlled rate liquid nitrogen freezing apparatus (Linde, Union Carbide Corp., New York). For thawing, vials were submerged briefly in a $37^{\circ} \mathrm{C}$ water bath, brought to $0^{\circ} \mathrm{C}$, and rapidly diluted with an equal volume of cold RPMI 1640 with $10 \%$ human serum. They were washed once in the cold, permitted to warm to room temperature for $30 \mathrm{~min}$, and then dispensed into microtiter trays as responding cells or treated to serve as stimulating cells. Controls were included to verify that each stimulating cell and each responder reacted suitably to several unrelated donors. All MLC experiments were repeated one to four times, usually with lymphocytes obtained on a different day from new samples of blood.

$H L A$ typing. Testing for HLA antigens was performed using a standard microcytotoxicity method (19). The HLA typing reagents used were obtained from the NIH Serum Bank, from other investigators, and from our own pregnancy serum screening program (20). These antisera permitted identification of all the HLA antigens and the World Health Organization recognized Workshop specificities belonging to the A (LA) and B (4) locus. The third segregant series ( $\mathrm{C}$ or $\mathrm{AJ}$ locus) was not investigated.

\section{RESULTS}

Evaluation of $M L C$ results. The effect of expressing MLC results as relative responses in 2-haplotype, 1-haplotype, and 0-haplotype difference cultures obtained in the course of family studies was examined. Since the results were expressed as a percentage of the 2-haplotype response, reactions resulting from 2-haplotype differences tended to cluster around 100\% (Fig. 1). When on the basis of HL-A genotyping there was a 1-haplotype difference between the responding and the stimulating cell, the reactions tended to cluster around $50 \%$. In the group of cultures where the stimulator had no LD determinant not present in the responder, stimulation was low or absent, ranging from 0 to $20 \%$. There was good separation between the 0-haplotype and the other two groups as shown by their $95 \%$ confidence limits (Fig. 1). When the 0-haplotype difference resulted from an LD heterozygous responder reacting to an LD homozygous stimulator higher values were often observed as has been found also by others (13). In the evaluation of MLC responses in subsequent experiments, a relative response of $38 \%$ was chosen on the basis of visual inspection of results as the upper limit for defining a low response. Later it was found on the basis of the $95 \%$ confidence limits of the whole high and low responder groups that the $38 \%$ relative response coincided 


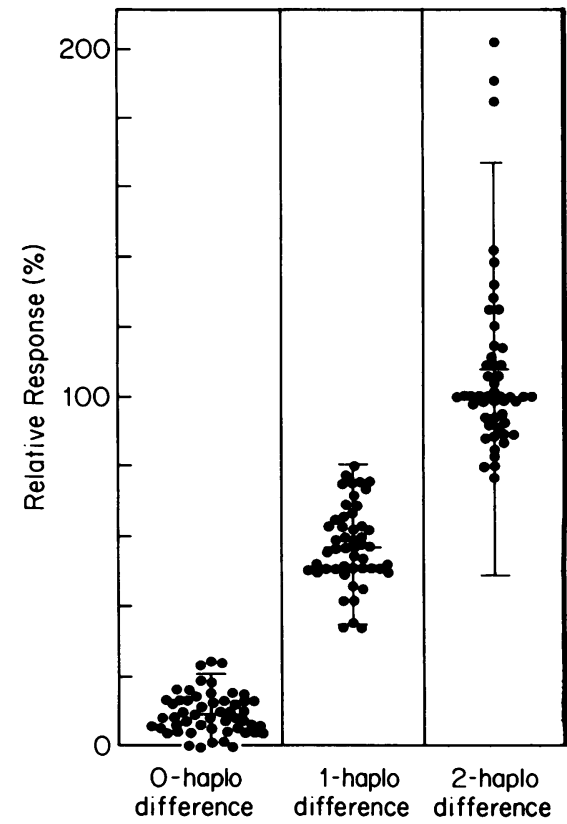

FIGURE 1 MLC results expressed as relative responses. These results were obtained from experiments performed in 35 families. The vertical bars give the $95 \%$ confidence limits of each group.

with a dividing line that accurately separated the two populations.

Low $M L C$ reactions in random $R A$ patients and controls. Having thus defined the interpretation of MLC results, random one-way cultures were performed in checkerboard fashion between 43 patients with RA and 45 non-RA subjects. The cultures were divided into four groups two of which consisted of RA responders stimulated either by other RA patients or by non-RA subjects ( $A$ and $B$ in Fig. 2), and the other two were non-RA control responders cultured with either RA or control stimulators ( $\mathrm{C}$ and $\mathrm{D}$ in Fig. 2). The results were evaluated as relative responses and those below $38 \%$ were considered low. In the group of RA responders vs. RA stimulators, 31 low MLC reactions were identified (Fig. 2A). Of interest is the fact that these low MLC reactions occurred repeatedly with the same RA stimulator cells. Only 8 out of the 43 RA patients studied functioned as low stimulators and the majority of the low reactions occurred with only two of these. Repeated tests with lymphocytes obtained from the same subjects on different days were found to be highly reproducible. The other $35 \mathrm{RA}$ stimulators always elicited normal responses.

In the group of control subjects cultured against RA stimulators six low reactions occurred. All of them were with the two RA stimulators who elicited low responses most frequently in the RA vs. RA group (Fig. 2).
In the cultures of RA patients against non-RA control subjects no low responses occurred. In the control group of cultures between non-RA subjects there were three low responses. The stimulator involved, J. L., a normal laboratory technician, was homozygous for the HLA antigens A1, B8, and LD homozygous by family study (21). The three low responders, all HLA-B8 positive, have the LD determinant DW3 (according to the new WHO nomenclature; previously called LD-8a or SR). Thus their low responses represent 0-haplotype reactions due to sharing of $\mathrm{LD}$ determinants.

Table I displays the results of cultures, using as stimulators, eight RA patients that produced low reactions with selected responders. Thus, responder N. D. gave a low reaction to A. C. (17\%), A. W. (35\%), and F. S. $(15 \%)$. Responder J. I. produced low responses to A. C., L. B., and J. B.; A. W. gave low MLC to A. C. and N. D.; L. W. had a low response to R. B.; and A. C. showed a low response to M. J. None of these reactions were completely without stimulation. They varied between 15 and 35 whereas the relative responses in autologous cultures were from 1 to $4 \%$. Thus, although not negative, the low responses stood out in comparison with the rest of the MLC results which varied between 57 and $234 \%$. Of the 37 unrelated pairs shown in Table $I$, low reactions were present in 10 , the
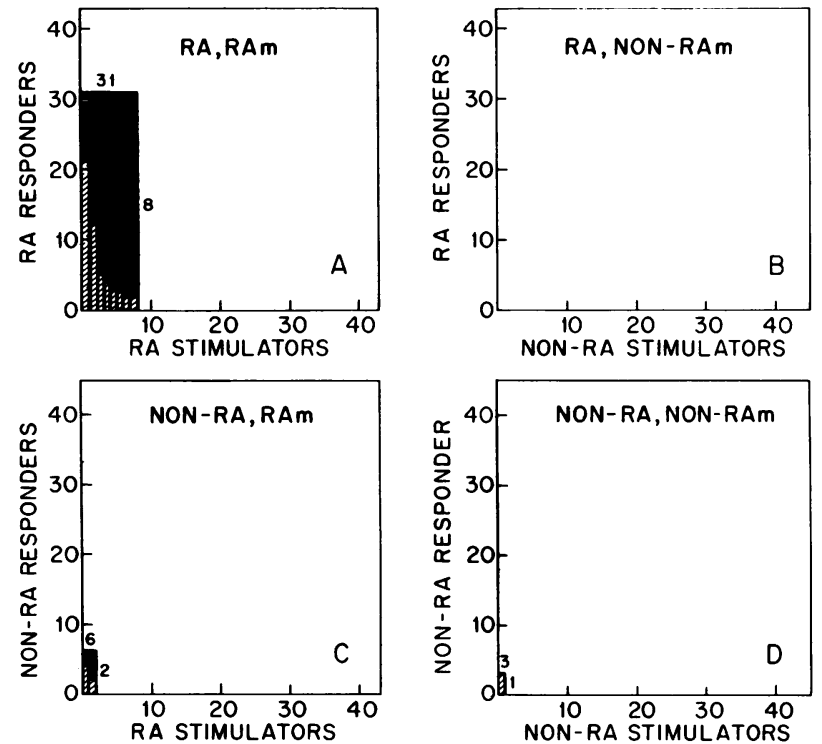

Figure 2 Low MLC reactions in random RA patients and controls. Group A : RA responders, RA stimulators; Group $B$ : RA responders, non-RA stimulators; Group C: nonRA responders, RA stimulators; and Group D: non-RA responders, non-RA stimulators. Low responses (relative response $<38 \%$ ) to each stimulator are indicated by vertical bars. The total of low responders and low stimulators is indicated by the rectangles (in black) and numbers given along their sides. For further details see text. 
TABLE I

MLC between Selected RA Patients Showing Low Responses to Eight RA Stimulators

\begin{tabular}{|c|c|c|c|c|c|c|c|c|c|}
\hline \multirow[b]{2}{*}{ Responders } & \multirow{2}{*}{$\begin{array}{c}\text { Medium } \\
\text { control }\end{array}$} & \multicolumn{8}{|c|}{ Stimulating cells } \\
\hline & & $\mathrm{ACm}$ & $\mathrm{AWm}$ & $\mathrm{LBm}$ & $\mathrm{FSm}$ & NDm & $\mathrm{RBm}$ & $\mathrm{JBm}$ & MJm \\
\hline \multirow[t]{3}{*}{ N. D. } & 250 & $874^{*}$ & 1,535 & 4,692 & 801 & 324 & 3,921 & 8,840 & 6,344 \\
\hline & & 2.7 & 4.7 & 14.5 & 2.5 & 1.0 & 12.1 & 27.3 & 19.6 \\
\hline & & 17 & 35 & 121 & 15 & 2 & 100 & 234 & 166 \\
\hline \multirow[t]{3}{*}{ J. I. } & 877 & 4,178 & 10,623 & 3,706 & 22,569 & 16,596 & 15,181 & 4,178 & 18,797 \\
\hline & & 3.1 & 7.9 & 2.8 & 16.7 & 12.3 & 11.3 & 3.1 & 13.9 \\
\hline & & 21 & 62 & 18 & 138 & 100 & 91 & 21 & 114 \\
\hline \multirow[t]{3}{*}{ A. W. } & 645 & 4,377 & 701 & 12,973 & 12,634 & 3,925 & 9,467 & 27,111 & 13,991 \\
\hline & & 6.2 & 1.0 & 18.5 & 18.0 & 5.6 & 13.5 & 38.7 & 20.0 \\
\hline & & 33 & 1 & 109 & 106 & 29 & 78 & 234 & 118 \\
\hline \multirow[t]{3}{*}{ L. W. } & 402 & 4,784 & 3,942 & 6,414 & 5,065 & 13,044 & 1,919 & 12,707 & 5,459 \\
\hline & & 11.5 & 9.4 & 15.3 & 12.1 & 31.2 & 4.6 & 30.4 & 13.1 \\
\hline & & 78 & 63 & 107 & 83 & 225 & 27 & 219 & 90 \\
\hline \multirow[t]{3}{*}{ A. C. } & 563 & 717 & 3,696 & 5,116 & 3,737 & 3,654 & 6,452 & 2,944 & 1,649 \\
\hline & & 1.0 & 5.2 & 7.1 & 5.2 & 5.1 & 9.0 & 4.1 & 2.3 \\
\hline & & 4 & 75 & 109 & 76 & 74 & 141 & 57 & 26 \\
\hline
\end{tabular}

* Results expressed as follows: Counts per minute, stimulation index, relative response (\%).

remaining 27 had perfectly normal responses. Thus the majority of the pairs demonstrated normal MLC stimulation even in this highly selected group of RA patients chosen to show low MLC responses.

Effect of medications on the MLC response in $R A$ patients. None of the patients used in these studies were receiving immunosuppressive drugs. The intake of other drugs was reviewed from the hospital and clinic records. To determine whether medications such as aspirin, prednisolone in small doses, and gold salts had any effect on the results of MLCs, groups of RA subjects and controls with normal responses and those with low MLC responses were compared (Table II). The median value of the 2-haplotype responses was used as an indication of the overall level of tritiated thymidine incorporation. There was no difference in this parameter between RA patients with and without low MLC responses while in the non-RA group, the six subjects with low MLC reactions had a somewhat lower 2-haplotype response (Table II). Aspirin was used by 23 out of 31 RA patients with low responses and by 9 of 12 that did not show a low response. The average intake of the drug was not significantly different between the two groups. There were more RA patients taking prednisolone in the low responder group but the two patients taking $10 \mathrm{mg} /$ day did not have any low responses. In both groups of RA patients, many were receiving gold salts but none of the controls were treated with this drug. Thus, it appears that there was no correlation between low responses and drug intake by these patients. It seems unlikely that the low responses observed could have been caused by these agents.

TABLE II

Effect of Medications on the MLC Response in RA Patients and Controls

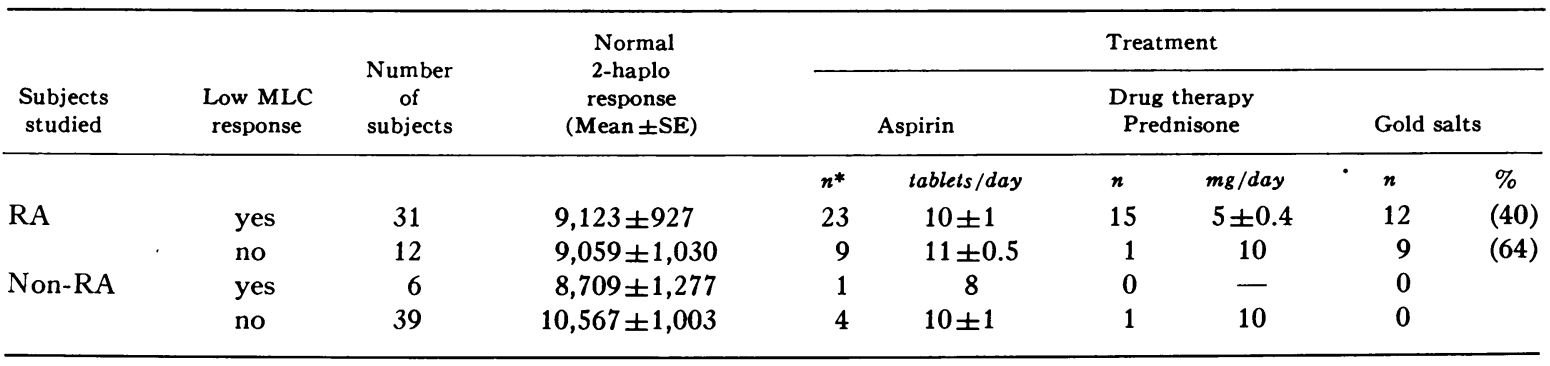

${ }^{*} n=$ Number of patients receiving drug. 
Effect of $R A$ serum and serum fractions on $M L C$ responses. To determine whether the low MLC reactions could have been due to inhibitory factors in the serum of these patients MLC were performed in the presence of serum from two RA patients (A. C. and A. W.) known to be frequent low stimulators. In six separate cultures, consisting of lymphocytes from three $\mathrm{RA}$ and three normal donors, up to $10 \%$ concentration of these RA serums produced little decrease in tritiated thymidine incorporation compared to the results obtained with $10 \%$ pooled normal human serum used in all the other experiments. In no case did a relative response of less than $38 \%$ result from the addition of RA serum.

In other experiments, $7 \mathrm{~S}$ and $19 \mathrm{~S}$ fractions, obtained by G-200 Sephadex chromatography from an RA serum known to contain high titer rheumatoid factor of both the $\operatorname{IgM}$ and $\operatorname{IgG}$ variety and also a monoclonal IgM rheumatoid factor (kindly supplied by Dr. Mario Andreis), were added to MLC of four control subjects and four RA patients known to produce normal responses. In no case was a low response generated by addition of these materials.

Effect of short-term culture and washing before $M L C$ on the low responses of $R A$ patients. Although the cultures were performed with washed lymphocytes incubated in medium containing pooled normal human serum the possibility was considered that the cells may have been coated by an inhibitory factor in vivo. There- fore, lymphocytes from patients known to produce low responses were cultured in medium with $20 \%$ pooled human serum for $24 \mathrm{~h}$ and washed two times before mixing with allogeneic cells. In Table III, are shown the results of four experiments performed with RA lymphocyte combinations previously known to produce low reactions. In experiment 1 , the response of $\mathrm{M}$. $\mathrm{H}$. to AWm with no pretreatment was $11 \%$. In parallel cultures performed on the same day the lymphocytes of the stimulator (A. W.) or the responder (M. H.) or both (A. W. and M. H.) had been cultured in medium with normal serum and washed before mixing with allogeneic cells. In every case the results of the MLC remained low. Three other experiments with essentially similar results are shown. Also in experiment 2, a culture starting with a somewhat higher value, the untreated lymphocytes giving a relative response of $32 \%$, 24-h incubation and washing of the lymphocytes did not result in recovery to a normal MLC response. In addition to the experiments shown in Table II, four additional experiments with cells from other donors were performed with essentially the same results.

Study of HLA antigens and MLC determinants in the family of patient $A$. $C$. Another possibility for production of very low MLC responses among RA patients would be the sharing of the major LD determinants. Thus if certain stimulators were LD homozygous, other patients possessing the same or similar LD determinants would be expected to produce very low MLC responses.

TABLE III

Effect of Short-Term Culture and Washing before MLC on the Low Responses of RA Lymphocytes*

\begin{tabular}{|c|c|c|c|c|c|c|}
\hline \multirow[t]{2}{*}{$\begin{array}{l}\text { Experiment } \\
\text { no. }\end{array}$} & \multirow[t]{2}{*}{$\begin{array}{l}\text { Responding } \\
\text { cell }\end{array}$} & \multirow[t]{2}{*}{$\begin{array}{l}\text { Stimulating } \\
\text { cell }\end{array}$} & \multirow[t]{2}{*}{$\begin{array}{l}\text { Lymphocytes } \\
\text { preincubated }\end{array}$} & \multirow{2}{*}{$\begin{array}{c}\begin{array}{c}\text { 2-haplo } \\
\text { MLC } \\
\text { response }\end{array} \\
c p m\end{array}$} & \multicolumn{2}{|c|}{$\begin{array}{l}\text { Response in test } \\
\text { culture }\end{array}$} \\
\hline & & & & & $c p m$ & $\%$ \\
\hline \multirow[t]{4}{*}{1} & M. H. & A. $\mathrm{W}$. & None & 4,481 & 448 & 11 \\
\hline & & & A. $W$. & 2,283 & 228 & 10 \\
\hline & & & M. H. & 1,667 & 295 & 18 \\
\hline & & & A. W. and M. H. & 1,930 & 281 & 14 \\
\hline \multirow[t]{4}{*}{2} & F. H. & A. $W$. & None & 3,561 & 1,125 & 32 \\
\hline & & & A. W. & 3,976 & 1,436 & 36 \\
\hline & & & F. H. & 1,498 & 351 & 23 \\
\hline & & & A. W. and F. H. & 2,467 & 810 & 33 \\
\hline \multirow[t]{3}{*}{3} & L. C. & A. C. & None & 7,823 & 2,058 & 26 \\
\hline & & & A. C. & 14,487 & 3,209 & 22 \\
\hline & & & L. C. & 39,835 & 8,466 & 19 \\
\hline \multirow[t]{2}{*}{4} & L. E. & A. C. & None & 2,095 & 440 & 21 \\
\hline & & & A. C. & 2,637 & 943 & 35 \\
\hline
\end{tabular}

* Lymphocytes were cultured in medium with $20 \%$ pooled human serum for $24 \mathrm{~h}$ and washed two times before mixing with allogeneic cells.

$\ddagger$ Relative response.

1152

P. Stastny 


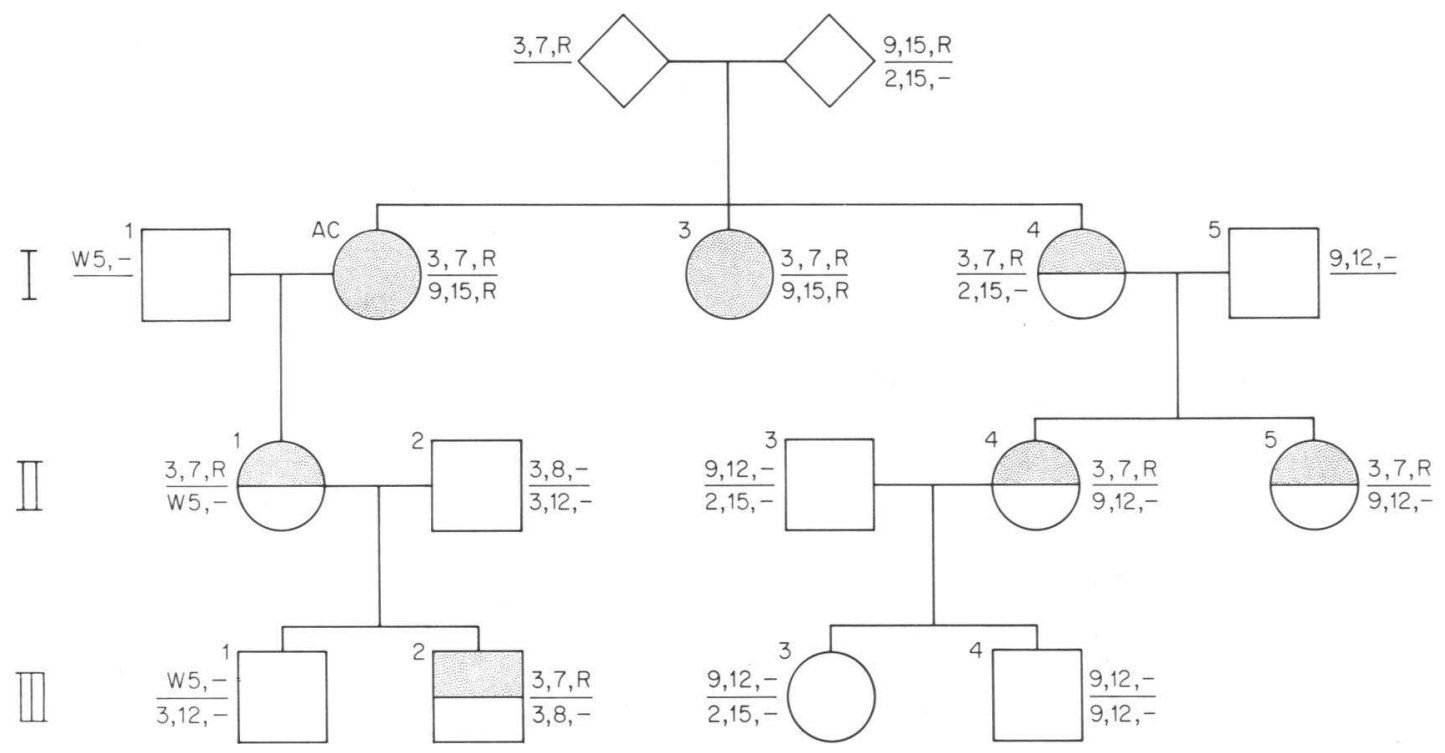

Figure 3 Family of patient A. C. Shown are the HLA and LD genotypes based on serologic typing for HLA-A and HLA-B and the interpretation of MLC results. AC and sister I,3 are $\mathrm{R}$ homozygous (full stippling); five other family members (with half stippling) have inherited $R$ in only one haplotype. In each of these $R$ was associated with the haplotype HLA-A3, B7. Detailed MLC results are given in Table IV.

In the case of patient A. C. (A. C. was the first RA stimulator in Fig. 1) it was shown that about half of the random adult RA patients tested as responders produced low responses. Therefore, the possibility that A. C. might be LD homozygous seemed reasonable and was examined by performing HLA and MLC tests among the members of her family. 12 individuals belonging to three generations were investigated. The results are summarized in Fig. 3. The haplotypes HLAA3, B7 and HLA-A9, BW15 were present in A. C. and in her sister I,3. The other sister $(I, 4)$ shared the haplotype HLA-A3. B7 and her other haplotype was HLA-A2, BW15. The HLA-A3, B7 haplotype was also present in subjects II, 1 ;I,4, and II,5 of the second generation and in subject III,2 of the third.

The results of MLC studies are shown in Table IV. A. C. and I,3 who were HLA identical were also mutually nonstimulatory. Several other family members produced very low response to A. C. (I,4; II,1; II,4; II,5 and III,2). In each case these were the persons that had received the $\mathrm{HLA}-\mathrm{A} 3, \mathrm{~B} 7$ haplotype. In the case II,1 and III,2, the haplotype was derived directly from A. C. In the other family members it was inherited through her sister I,4. The reciprocal reactions of $\mathrm{A}$. C. responding against the same family members in every case produced strong stimulation, indicating that the other LD haplotype in these persons was not similar to that of A. C. In Fig. 3, A. C. and I,3 are shown to be homozygous (full stippled area). The other family members that gave very low responses to $A$. C. are shown as heterozygous (half stippled area). The LD determinant defined by A. C. has been called " $R$ ". Individual $I, 3$ should be also $R$ homozygous. In fact when $\mathrm{I}, 3$ was used as stimulator the reactions were in every case much higher than those to A. C., with the exception of the reactions between the two where $\mathrm{I}, 3 \times \mathrm{ACm}$ $=5 \%$ and A. C. $\times 1,3 \mathrm{~m}=13 \%$. There are several possibilities to explain the differences between A. C. and I,3 when used as stimulators. The most likely one is that I,3 stimulating cells although inactivated with mitomycin $\mathrm{C}$ were capable of recognizing the nonshared haplotype in the heterozygous cells (I,4; II,1; II,4; II,5 and III,2) and of producing a blastogenic factor. Such a factor has been shown to be produced by mitomycintreated lymphocytes (22).

Frequency of $L D$-typing reactions to $A$. C. and $A$. W. Two rheumatoid patients when used as stimulators were responsible for the majority of the low MLC reactions observed. One of them was A. C., who was shown by family study to be LD homozygous. The other was A. W., a black woman with typical RA whose family was unfortunately not available. The frequency of LDtyping reactions to lymphocytes from these two donors was investigated in a group of 50 patients with RA and 50 nonrheumatoid controls. In the RA group, 24 patients gave typing responses to A. C. and not to A. W.; 10 patients showed typing reactions to A. W. Altogether $68 \%$ of the RA patients appeared to possess LD deter- 
TABLE IV

Results of MLC Study in Family AC

\begin{tabular}{|c|c|c|c|c|c|c|c|c|c|c|c|c|c|}
\hline $\begin{array}{l}\text { Responding } \\
\text { cells* }\end{array}$ & $\begin{array}{l}\text { Medium } \\
\text { control }\end{array}$ & ACm & $\mathrm{I}, 3 \mathrm{~m}$ & $\mathrm{I}, 4 \mathrm{~m}$ & $\mathrm{II}, 1 \mathrm{~m}$ & $\mathrm{II}, 2 \mathrm{~m}$ & II, $3 \mathrm{~m}$ & $\mathrm{II}, \mathbf{4 m}$ & II, $5 \mathrm{~m}$ & $\mathrm{III}, 1 \mathrm{~m}$ & $\mathrm{II} \mathrm{I}, 2 \mathrm{~m}$ & III, 3 & III,4m \\
\hline \multirow[t]{3}{*}{ A. C. } & 264 & 3478 & 763 & 3,325 & 4,180 & 3,620 & 8,411 & 3,001 & 2.107 & 3.717 & 3,590 & 6,432 & 8,174 \\
\hline & & 1.0 & 2.2 & 9.6 & 12.1 & 10.4 & 24.2 & 8.7 & 6.1 & 10.7 & 10.3 & 18.5 & 23.6 \\
\hline & & 2 & 13 & 78 & 100 & 86 & 208 & 70 & 47 & 88 & 85 & 157 & 202 \\
\hline \multirow[t]{3}{*}{$\mathrm{I}, 3$} & 956 & 1,376 & 1,714 & 9,546 & 9.683 & 11,869 & 14,110 & 7.493 & 9,190 & 5.553 & 10,030 & 13,683 & 18,193 \\
\hline & & 0.8 & 1.0 & 5.6 & 5.6 & 6.9 & 8.2 & 4.4 & 5.4 & 3.2 & 5.8 & 8.0 & 10.6 \\
\hline & & 5 & 9 & 98 & 100 & 125 & 151 & 75 & 94 & 53 & 104 & 146 & 197 \\
\hline \multirow[t]{3}{*}{ I.4 } & 1,014 & 1,900 & 4,877 & 1,146 & 7,462 & 15.624 & 13,463 & 11,846 & 5,979 & 6,248 & 12,085 & 16,107 & 24,176 \\
\hline & & 1.7 & 4.3 & 1.0 & 6.5 & 13.6 & 11.7 & 10.3 & 5.2 & 5.4 & 10.5 & 14.0 & 15.6 \\
\hline & & 8 & 36 & 1 & 59 & 135 & 115 & 100 & 46 & 48 & 102 & 139 & 156 \\
\hline \multirow[t]{3}{*}{ II, 1} & 1,733 & 3,355 & 6,922 & 15,735 & 2,079 & 19,882 & 22,994 & 13,071 & 16.007 & 6.956 & 14,296 & 16,719 & 24,176 \\
\hline & & 1.6 & 3.3 & 7.6 & 1.0 & 9.6 & 11.1 & 6.3 & 7.7 & 2.9 & 6.9 & 8.0 & 11.6 \\
\hline & & 11 & 35 & 95 & 2 & 124 & 145 & 77 & 97 & 45 & 86 & 102 & 153 \\
\hline \multirow[t]{3}{*}{ II, 2} & 2,717 & 8,473 & 9,933 & 15,720 & 18,809 & 3,581 & 25,773 & 13,553 & 9,904 & 7,759 & 12.295 & 27,923 & 27,372 \\
\hline & & 2.4 & 2.8 & 4.4 & 5.2 & 1.0 & 7.2 & 3.8 & 2.8 & 2.2 & 3.4 & 7.8 & 7.6 \\
\hline & & 44 & 55 & 100 & 123 & 7 & 177 & 83 & 55 & 39 & 73 & 193 & 189 \\
\hline \multirow[t]{3}{*}{ II, 3} & 543 & 11,674 & 14,306 & 13,458 & 14,144 & 24,497 & 847 & 20,307 & 13,528 & 9.780 & 20,023 & 15.462 & 13,893 \\
\hline & & 13.8 & 16.9 & 15.9 & 16.7 & 28.9 & 1.0 & 24.0 & 16.0 & 11.5 & 23.6 & 18.3 & 16.4 \\
\hline & & 83 & 102 & 96 & 101 & 178 & 2 & 147 & 96 & 68 & 145 & 111 & 99 \\
\hline \multirow[t]{3}{*}{ II.4 } & 242 & 2.577 & 5,789 & 17,355 & 10,017 & 10,897 & 30,840 & 2,424 & 17,195 & 6,497 & 6,762 & 25,161 & 21,343 \\
\hline & & 1.1 & 2.4 & 7.2 & 4.1 & 4.5 & 12.7 & 1.0 & 7.1 & 2.7 & 2.8 & 10.4 & 8.8 \\
\hline & & 16 & 37 & 114 & 65 & 71 & 204 & 15 & 113 & 42 & 43 & 166 & 141 \\
\hline \multirow[t]{3}{*}{ II, 5} & 651 & 1,876 & 4,807 & 9,692 & 11,446 & 14,723 & 11,531 & 11,495 & 828 & 12,883 & 6,867 & 18,138 & 15,894 \\
\hline & & 2.3 & 5.8 & 11.7 & 13.8 & 17.8 & 13.9 & 13.9 & 1.0 & 15.6 & 8.3 & 21.9 & 19.2 \\
\hline & & 11 & 38 & 83 & 99 & 130 & 100 & 100 & 2 & 113 & 57 & 161 & 140 \\
\hline \multirow[t]{3}{*}{ III, 1} & 220 & 5,055 & 9,288 & 8,520 & 7,677 & 11,821 & 18,197 & 12,638 & 11,125 & 870 & 15,032 & 17.795 & 13.536 \\
\hline & & 5.8 & 10.7 & 9.8 & 8.8 & 13.6 & 20.9 & 14.5 & 12.8 & 1.0 & 17.3 & 20.4 & 15.6 \\
\hline & & 43 & 81 & 74 & 66 & 103 & 160 & 110 & 97 & 6 & 132 & 156 & 118 \\
\hline \multirow[t]{3}{*}{ III,2 } & 825 & 4,166 & 7,427 & 15,154 & 15,682 & 15,676 & 18,951 & 8,850 & 13,049 & 6.819 & 1,573 & 17,570 & 17,893 \\
\hline & & 2.6 & 4.7 & 9.6 & 10.0 & 10.0 & 12.0 & 5.6 & 8.3 & 5.0 & 1.0 & 11.2 & 11.4 \\
\hline & & 20 & 43 & 99 & 103 & 103 & 125 & 53 & 84 & 46 & 5 & 115 & 118 \\
\hline \multirow[t]{3}{*}{ III, 3} & 416 & 8,307 & 12,834 & 11,453 & 17.810 & 12,701 & 12,696 & 15,175 & 9.490 & 8,097 & 14,368 & 952 & 6,499 \\
\hline & & 8.7 & 13.5 & 12.0 & 18.7 & 13.3 & 13.3 & 15.9 & 10.0 & 8.5 & 15.1 & 1.0 & 6.8 \\
\hline & & 64 & 101 & 90 & 142 & 100 & 100 & 120 & 74 & 62 & 114 & 4 & 49 \\
\hline \multirow[t]{3}{*}{ III,4 } & 1,877 & 14,457 & 23,263 & 16,444 & 27,287 & 28,274 & 23,069 & 21,849 & 16,644 & 14,658 & 27,097 & 11,829 & 2,547 \\
\hline & & 5.7 & 9.1 & 6.5 & 10.7 & 11.1 & 9.1 & 8.6 & 6.5 & 5.8 & 10.6 & 4.6 & 1.0 \\
\hline & & 71 & 122 & 83 & 144 & 150 & 120 & 114 & 84 & 73 & 143 & 57 & 4 \\
\hline
\end{tabular}

* For identification of individual family members refer to Fig. 2.

‡ Stimulating cells were treated with mitomycin C.

$\$$ Results are expressed as follows in vertical sequence: counts per minute, followed by stimulation index, and relative response (\%).

minants that were defined with these two typing cells (Table V). The 50 control subjects who were tested simultaneously with the RA patients showed a combined frequency of only $12 \%$.

TABLE V

Frequency of LD-Typing Reactions to Cells from $A$. C. and $A$. W.

\begin{tabular}{|c|c|c|c|c|}
\hline \multirow[b]{2}{*}{ Subjects } & \multirow{2}{*}{$\begin{array}{c}\text { Number } \\
\text { investigated }\end{array}$} & \multicolumn{2}{|c|}{$\begin{array}{c}\text { Number with low } \\
\text { response* }\end{array}$} & \multirow{2}{*}{$\begin{array}{l}\text { Combinec } \\
\text { frequency }\end{array}$} \\
\hline & & $A C_{x}$ & $\mathrm{AW}_{\mathbf{x}}$ & \\
\hline & & & & $\%$ \\
\hline RA & 50 & 24 & 10 & 68 \\
\hline Controls & 50 & 4 & 2 & 12 \\
\hline
\end{tabular}

* Relative response less than $38 \%$.

\section{DISCUSSION}

An important finding in the present experiments was that the majority of MLC reactions in patients with RA were normal. The results were in that regard not identical to those of previous workers who reported absence of stimulation or very low responses in mixed cultures between over half of the RA patients tested $(7,8)$. Among the factors that might have a bearing on this difference are the use in the present work of purified lymphocyte preparations obtained by the Ficoll-Hypaque method, which consistently contained less than $2 \%$ granulocytes and few erythrocytes; the careful washing of the cells to remove serum factors and drugs; the use of pooled normal human serum to supplement the culture medium; and the use of the relative response method to evaluate the reactions. There is no indication in the results obtained in the present study to suggest that lymphocyte transformation in RA patients may 
be defective or unreliable. Other authors have come to similar conclusions (23).

When the effect of drugs taken by RA patients was examined, no correlation was found between low responses and the intake of various medications. Thus although aspirin present in the culture medium is known to inhibit lymphocyte responses (24) and reduced responses have been reported in patients after oral intake of aspirin (25) there was no evidence to support the notion that the highly selective low responses observed in the present experiments were due to aspirin or other drugs. Since the results were normalized and expressed as relative responses a small nonspecific reduction of counts would probably not have influenced the final interpretation of the MLC results.

Although it seems unlikely that enough serum was retained after washing the cells to influence the culture results, two other circumstances that might have influenced the outcome were considered. The first was that lymphocytes of certain patients could have been coated by inhibitory factors in vivo. Marked reduction of MLC responsiveness in patients with systemic lupus erythematosus apparently caused by lymphocyte autoantibodies was shown by Wernet et al. (26) to be reversible after short-term culture in medium with normal serum. In the present experiments it was found that culture for $24 \mathrm{~h}$ and washing before admixture with allogeneic cells had no effect on the low responses observed. Since no significant increase in either responsiveness or stimulating capacity was observed after incubation times which should have allowed at least some removal of surface components, the possibility of blocking of the lymphocytes by antibodies bound in vivo seems unlikely.

The second possibility considered was the production of inhibitory factors by $B$ cells in the course of the cultures. Since such materials would most likely be present in the serum of the lymphocyte donors a number of experiments were performed adding whole serum or serum fractions from patients that produced low MLC responses. This never generated low responses in either normal or RA lymphocyte pairs of the high responder groups. Similarly, polyclonal IgM and IgG rheumatoid factors and a monoclonal IgM rheumatoid factor did not significantly block the MLC reactions.

Having ruled out a variety of extrinsic factors and since a nonspecific cellular defect would not account for the observations, the next possibility considered was that of sharing of genetically controlled LD determinants. Abundant evidence has been accumulated to indicate that MLC stimulation is under genetic control regulated by a separate locus called HLA-D (previously MLR-S or LD-1) closely linked to the HLA-B locus (previously Four or SD-2). Using lymphocytes from individuals homozygous at the HLA-D locus as MLCtyping cells (12-15) several alleles of the HLA-D locus have been identified. A number of these groups show strong association with alleles of the HLA-B locus (28). A strong association has also been reported between the HLA-D allele DW2 (previously called LD$7 \mathrm{a})$ and the development of multiple sclerosis (29). In fact a patient with multiple sclerosis homozygous for DW2 was used for MLC typing. In multiple sclerosis also an association with HLA-A3 and HLA-B7, has been recognized in several laboratories $(30-32)$. No such association with HLA-A or HLA-B locus alleles appears to exist in RA (33-35). Nevertheless sharing of alleles of the HLA-D locus could occur independently of the other HLA genes and would provide a satisfactory explanation of the present experimental findings.

The results of the family study showed that patient A. C. who was the stimulator most frequently involved in low responses, was indeed HLA-D homozygous. Because this LD determinant was found in a patient with RA it has temporarily been called "R". 6 of the 11 other persons of her family gave very low MLC responses to her cells. All of them appeared to share the same HLA-A3, B7 haplotype. A. C. and I,3 were unresponsive in both directions suggesting that $I, 3$ was also homozygous, which is to be expected since she was by serology HLA identical. The other five family members with low reactions to A. C. appear to be heterozygous as evidenced by the fact that they stimulated A. C.

It is interesting that individual I,3 produced higher reactions than A. C. when used as stimulator for the $R$ heterozygous family members. The reason for this is not known. Since I,3 did not stimulate A. C., the higher values obtained when heterozygous responders were used are likely due to production of blastogenic factor (22). A similar observation was made with two HLADW3 homozygous cells recently studied in this laboratory. Subjects J. L. and J. G. both HLA-DW3 homozygous and mutually nonstimulatory were used as stimulators in cultures with several DW3 heterozygous cells. J. L. produced very low stimulation whereas reactions to J. G. were considerably higher. Preliminary results indicate that the difference was due to production of blastogenic factor. ${ }^{2}$

Since A. C. is HLA-D homozygous it seems likely that the frequent low MLC reactions of RA patients in these studies constitute "typing responses" and indicate that these patients carry the same or a similar HLA-D determinant. It is apparent from Fig. 1, that a similar HLA-D determinant must have been present also in 4 of the 45 non-RA control responders. The

'Stastny, P. Unpublished observations. 
family study of one of these indicated that the HLA-D determinant " $R$ " was inherited from the mother in association with one of her HLA haplotypes (16). Thus it appears that " $R$ " is frequently found in patients with RA but can be found also in normal individuals and in either situation is inherited in linkage with HLA.

In the course of the 6th International Histocompatibility Workshop it has been possible to compare lymphocytes from patient A. C. with other homozygous typing cells from 14 LD laboratories. Results of these studies, which will be reported in detail elsewhere, have shown that several other homozygous cells possess determinants similar to those of A. C. (36). These cells showed strong associations in the joint analysis of the workshop LD data and characterize an allele which has received the WHO designation HLA-DW4 (28).

Further studies of families of two other RA patients causing low MLC stimulation have also shown them to be HLA-D homozygous for determinants which although similar are not identical to those of A. C. (36). Thus it seems likely that all or most of the low MLC reactions observed in $\mathrm{RA}$ patients can be explained on the basis of sharing of inherited MLC determinants. In a preliminary assessment, the frequency of these determinants in non-RA subjects was $12 \%$, and in RA patients it was $68 \%$. More detailed population studies using several LD homozygous typing cells will be reported in a subsequent publication. ${ }^{3}$

There has been considerable debate about the role of genetic factors in RA and the results of different studies have been far from uniform (37). A survey of Blackfeet and Pima Indians gave no evidence of striking genetic factors, but did show a higher prevalence of RA in siblings and parents of affected persons than in agematched controls (38). The results suggested environmental factors played the major role in the appearance of the disease. In other studies a genetic influence was suggested in adults (39), and in children with RA (40). The results of the present work open a new approach to inquiry into the genetics of RA. Because of the known proximity of the locus controlling strong MLC stimulation to those regulating certain specific immune responses in mice (41) and in rhesus monkeys (42) it is attractive to speculate that an Ir gene may be involved. The rapidly developing knowledge of the HLA chromosomal region which includes also loci for certain complement components (43), cell surface receptors (44), and disease associations (45) would indicate that many other possibilities must be considered. Since many of these possibilities are open to experimental testing with tools already available, further exploration should lead to an understanding of the mechanisms involved in

\footnotetext{
${ }^{3}$ Stastny, P. Manuscript in preparation.
}

predisposition and possibly also provide clues regarding other factors involved in the development of RA.

\section{ACKNOWLEDGMENTS}

The author would like to thank Laurie Poppe and Ben Perryman for their expert technical assistance and Carol McDonald Reynolds for assistance in the preparation of this manuscript.

This work was supported in part by National Institutes of Health grant no. 1-R01-AI-12563-01.

\section{REFERENCES}

1. Ziff, M. 1974. Relation of cellular infiltration of rheumatoid synovial membrane to its immune response. Arthritis Rheum. 17: 313-319.

2. Froland, S. S., J. B. Natvig, and G. Husby. 1973. Immunological characterization of lymphocytes in synovial fluid from patients with rheumatoid arthritis. Scand. J. Immunol. 2: 67-73.

3. Winchester, R. J., J. B. Winfield, F. Siegal, P. Wernet, Z. Bentwich, and H. G. Kunkel. 1974. Analyses of lymphocytes from patients with rheumatoid arthritis and systemic lupus erythematosus. Occurrence of interfering cold-reactive anti-lymphocyte antibodies. J. Clin. Invest. 54 : 1082-1092.

4. Brenner, A. I., M. A. Scheinberg, and E. S. Cathcart. 1975. Surface characteristics of synovial fluid and peripheral blood lymphocytes in inflammatory arthritis. Arthritis Rheum. 18 : 297-303.

5. Smiley, J. D., C. Sachs, and M. Ziff. 1968. In vitro synthesis of immunoglobulin by rheumatoid synovial membrane. J. Clin. Invest. 47: 624-632.

6. Stastny, P., M. Rosenthal, M. Andreis, and M. Ziff. 1975. Lymphokines in the rheumatoid joint. Arthritis Rheum. 18: 237-243.

7. Astorga, G. P., and R. C. Williams, Jr. 1969. Altered reactivity in mixed lymphocyte culture of lymphocytes from patients with rheumatoid arthritis. Arthritis Rheum. 12 : $547-554$.

8. Hedberg, H., B. Källén, B. Löw, and O. Nilsson. 1971. Impaired mixed leucocyte reaction in some different diseases notably multiple sclerosis and various arthritides. Clin. Exp. Immunol. 9: 201-207.

9. Yunis, E. J., J. M. Plate, F. E. Ward, H. F. Seigler, and D. B. Amos. 1971. Anomalous MLR responsiveness among siblings. Transplant. Proc. 3: 118-120.

10. Eijsvoogel, V. P., L. Koning, L. de Groot-Kooy, L. Huismans, J. J. van Rood, A. van Leeuwen, and E. D. du Toit. 1972. Mixed lymphocyte culture and HL-A. Transplant. Proc. 4 : 199-204.

11. Dupont, B., R. A. Good, G. S. Hansen, C. Jersild, L. Staub-Nielsen, B. H. Park, A. Svejgaard, M. Thomsen, and E. J. Yunis. 1974. Two separate genes controlling stimulation in mixed lymphocyte reaction in man. Proc. Natl. Acad. Sci. U. S. A. $71: 52-56$.

12. Dupont, B., C. Jersild, G. S. Hansen, L. S.-Nielsen, M. Thomsen, and A. Svejgaard. 1973. Typing for MLC determinants by means of LD-homozygous and LD-heterozygous test cells. Transplant. Proc. 5: 1543-1549.

13. Jørgensen, F., L. U. Lamm, and F. Kissmeyer-Nielsen. 1973. Mixed lymphocyte cultures with inbred individuals: an approach to MLC typing. Tissue Antigens. 3: 323-339.

14. Mempel, W., H. Grosse-Wilde, P. Baumann, B. Netzel, I. Steinbauer-Rosenthal, J. Scholz, J. Bertram. and E. D. Albert. 1973. Population genetics of the MLC response: 
trying for MLC determinants using homozygous and heterozygous reference cells. Transplant. Proc. 5: 15291534.

15. van den Tweel, J. G., A. Blusse van Oud Alblas, J. J. Keuning, E. Goulmy, A. Termijtelen, M. L. Bach, and J. J. van Rood. 1973. Typing for MLC (LD): I. Lymphocytes from cousin-marriage offspring as typing cells. Transplant. Proc. 5 : 1535-1538.

16. Stastny, P. 1974. Mixed lymphocyte culture typing cells from patients with rheumatoid arthritis. Tissue Antigens. 4 : 571-579.

17. Hartzmann, R. J., M. L. Bach, F. H. Bach, G. B. Thurman, and K. W. Sell. 1972. Precipitation of radioactively labeled samples: a semiautomatic multiplesample processor. Cell. Immunol. 4: 182-186.

18. Böyum, A. 1968. Isolation of mononuclear cells and granulocytes from human blood. Isolation of mononuclear cells by one centrifugation and of granulocytes by combining centrifugation and sedimentation of Ig. Scand. J. Clin. Lab. Invest. 21 (Suppl.) : 77-89.

19. Mittal, K. K., M. R. Mickey, D. P. Singal, and P. I. Terasaki. 1968. Serotyping for homotransplantation. XVIII. Refinement of microdroplet lymphocyte cytotoxicity test. Transplantation (Baltimore). 6: 913-927.

20. Stastny, P. 1972. Tissue typing antisera from immunization by pregnancy. Tissue Antigens. 2: 123-127.

21. Sasazuki, T., A. McMichael, R. Payne, F. C. Grumet, R. Radvany, B. Colombe, H. McDevitt, P. Stastny, L. Marchuk, and J. Dosseter. 1975. New and previously recognized MLC alleles. In Histocompatibility Testing. F. Kissmeyer-Nielsen, editor. Munksgaard, A/S, Copenhagen. In press.

22. Hirschberg, H., B. Rankin, and E. Thorsby. 1974. Production of blastogenic factor by mitomycin-treated cells in mixed lymphocyte cultures. Transplantation (Baltimore). $17: 323-325$.

23. Metzger, A. L., G. Opelz, R. Bluestone, and P. I. Terasaki. 1974. Mixed leukocyte culture (MLC) in rheumatoid arthritis (RA). J. Rheumatol. 1:(Suppl.): 530. (Abstr.)

24. Opelz, G., P. I. Terasaki, and A. A. Hirata. 1973. Suppression of lymphocyte transformation by aspirin. Lancet. II : $478-480$.

25. Crout, J. E., B. Hepburn, and R. E. Ritts, Jr. 1975. Suppression of lymphocyte transformation after aspirin ingestion. N. Engl. J. Med. 292: 221-223.

26. Wernet, P., R. Thoburn, A. Moore, and H. G. Kunkel. 1974. Blockage of responder and stimulator lymphocyte surface structures and the shedding phenomenon mediated by human anti-lymphocyte sera in tissue culture. In Lymphocyte recognition and effector mechanisms. Proc. Leucocyte Cult. Conf. 8: 543-552.

27. WHO-IUIS HLA Nomenclature Committee. 1975. Nomenclature for factors of the HLA system. In Histocompatibility Testing. F. Kissmeyer-Nielsen, editor. Munksgaard, A/S, Copenhagen. In press.

28. Joint report of the 6th International Histocompatibility Workshop Conference. II. Typing for MLC determinants. In Histocompatibility Testing 1975. F. Kiss-
meyer-Nielsen, editor. Munksgaard, A/S, Copenhagen. In press.

29. Jersild, C., T. Fogg, G. S. Hansen, M. Thomsen, A. Svejgaard, and B. Dupont. 1973. Histocompatibility determinants in multiple sclerosis with special reference to clinical course. Lancet. II : 1221-1225.

30. Jersild, C., A. Svejgaard, and T. Fog. 1972. HL-A antigens and multiple sclerosis. Lancet. I: 1240-1241.

31. Bertrams, J., E. Kuwert, and V. Leidtke. 1972. HL-A antigens and multple sclerosis. Tissue Antigens. 2: 405408.

32. Naito, S., N. Namerow, M. R. Mickey, and P. I. Terasaki. 1972. Multiple sclerosis: association with HL-A 3. Tissue Antigens. 2: 1-4.

33. Lies, R. B., R. P. Messner, and G. M. Troup. 1972. Histocompatibility antigens in rheumatoid arthritis. Arthritis Rheum. 15: 524-529.

34. Seignalet, J., J. Clot, J. Sany, and H. Serre. 1972. HL-A antigens in rheumatoid arthritis. Vox Sang. 23: 468471.

35. Schlosstein, L., P. I. Terasaki, R. Bluestone, and C. M. Pearson. 1973. High association of an HL-A antigen, W27, with ankylosing spondylitis. N. Engl. J. Med. 288: 704-706.

36. Stastny, P. 1975. MLC determinants associated with rheumatoid arthritis. In Histocompatibility Testing 1975. F. Kissmeyer-Nielsen, editor. Munksgaard, A/S, Copenhagen. In press.

37. O'Brien, W. M. 1967. The genetics of rheumatoid arthritis. Clin. Exp. Immunol. 2: 785-802.

38. Bennett, P. H., and T. A. Burch. 1968. The genetics of rheumatoid arthritis. Excerpta Med. Int. Congr. Ser. 148. 136-147.

39. Lawrence, J. S., and P. H. N. Wood. 1968. Genetic Influences in rheumatoid arthritis. In Rheumatic Diseases. J. J. R. Duthie and W. R. M. Alexander, editors. The Williams \& Wilkins Co., Baltimore. 20-28.

40. Ansell, B. M., E. G. L. Bywaters, and J. S. Lawrence. 1968. Family studies in Still's disease (Juvenile RA). Excerpta Med. Int. Congr., Ser. 148. 229-234.

41. McDevitt, H. O., and B. Benacerraf. 1969. Genetic control of specific immune responses. Adv. Immunol. 2: 31-74.

42. Dorf, M. E., H. Balner, and B. Benacerraf. 1975. The major histocompatibility complex of rhesus monkeys (RhL-A) : VI. Mapping of RhL-A-linked immune-response genes. Transplant. Proc. 7(Suppl.) : 21-24.

43. Fu, S. M., F. Stern, H. G. Kunkel, B. Dupont, J. A. Hansen, N. K. Day, R. A. Good, C. Jersild, and M. Fotion. 1975. Mixed lymphocyte culture determinants and C2 deficiency: LD-7a associated with C2 deficiency in four families. J. Exp. Med. 142: 495-506.

44. Katz, D. H., and B. Benacerraf. 1975. The function and interrelationships of $\mathrm{T}$-cell receptors, Ir genes and other histocompatibility gene products. Transplant. Rev. 22: 175-195.

45. Svejgaard, A., P. Platz, L. P. Ryder, L. S.-Nielsen, and M. Thomsen. 1975. HL-A and disease associations -a survey. Transplant. Rev. 22: 3-43. 